Check for updates

Cite this: RSC Adv., 2018, 8, 9775

\title{
Optimization of 3D ZnO brush-like nanorods for dye-sensitized solar cells $\uparrow$
}

\author{
Simona Pace, (DD a Alessandro Resmini, ${ }^{a}$ Ilenia G. Tredici, ${ }^{a}$ Alessandro Soffientini, ${ }^{a}$ \\ Xuan Li, ${ }^{\text {b }}$ Steve Dunn, ${ }^{\text {bc }}$ Joe Briscoe (D) ${ }^{* b}$ and Umberto Anselmi-Tamburini (D) *a
}

In a dye-sensitized solar cell (DSSC) the amount of adsorbed dye on the photoanode surface is a key factor that must be maximized in order to obtain enhanced DSSC performance. In this study 3D ZnO nanostructures, named brush-like, are demonstrated as alternative photoanodes. In these structures, long $\mathrm{ZnO}$ nanorods are covered with a metal-organic precursor, known as a layered-hydroxide zinc salt (LHZS), which is subsequently converted to crystalline ZnO using two-step annealing. The LHZS is able to easily grow on any surface, such as the $\mathrm{ZnO}$ nanorod surface, without needing the assistance of a seed-layer. Brush-like structures synthesized using different citrate concentrations in the growth solutions and different annealing conditions are characterized and tested as DSSC photoanodes. The best-performing structure reported in this study was obtained using the highest citrate concentration (1.808 $\mathrm{mM})$ and the lowest temperature annealing condition in an oxidative environment. Conversion efficiency as high as $1.95 \%$ was obtained when these brush-like structures were employed as DSSC photoanodes. These results are extremely promising for the implementation of these innovative structures in enhanced DSSCs, as well as in other applications that require the maximization of surface area exposed by $\mathrm{ZnO}$ or similar semiconductors, such as gas- or bio-sensing or photocatalysis.

Received 7th December 2017

Accepted 21st February 2018

DOI: $10.1039 / c 7 r a 13128 c$

rsc.li/rsc-advances and a free electron is injected into the semiconductor and travels through it to the external circuit. The dye molecule is regenerated using a liquid electrolyte, usually $\mathrm{I}^{-} / \mathrm{I}_{3}{ }^{-}$; finally a platinum counter-electrode regenerates the electrolyte couple and closes the circuit.

In this cell, to obtain high performance, it is necessary that both the rate of the electron injection from the dye into the semiconductor and the rate of the electron transport from the semiconductor surface to the anode are higher than the rate of the recombination processes. ${ }^{4,5}$ To achieve this high performance and increase the percentage of injected electrons that reach the external circuit, each component of the DSSC needs to be optimized.

Among all the components, an optimized semiconductor material is of particular interest since both the amount of dye adsorbed and the probability that an excited electron reaches the external circuit depend on its structural and electronic properties. ${ }^{6} \mathrm{TiO}_{2}$ is the material usually employed as photoanode in $\mathrm{DSSCs}^{7}$ and the highest efficiency reported so far is about $14 \%{ }^{8}$ In a DSSC, $\mathrm{TiO}_{2}$ is usually present as a nanoporous film whose large surface area enables a high concentration of adsorbed dye. ${ }^{9-11}$ However, when this nanostructure is employed, the electrons must pass across many grain boundaries; consequently, both the resistivity to their flow and the recombination probability increase. ${ }^{12}$ To improve DSSC efficiency, many different morphologies have been proposed in recent years, such as nanorods ${ }^{13}$ or nanowires. ${ }^{14}$ These 1D
${ }^{a}$ Department of Chemistry, University of Pavia, Italy. E-mail: tau@unipv.it

${ }^{b}$ School of Engineering and Materials Science and Materials Research Institute, Queen Mary University of London, London, UK. E-mail: j.briscoe@qmul.ac.ukc

${ }^{c}$ Engineering and Technology, University of Hertfordshire, College Lane Campus, Hatfield, AL10 9AB, UK

$\dagger$ Electronic supplementary information (ESI) available. See DOI: 10.1039/c7ra13128c 
morphologies show high surface area on which the dye can adsorb, as well as a direct path for the electron flow from the semiconductor-dye interface to the external circuit. When these 1D morphologies are employed, the probability that the electrons reach the external circuit is increased, ${ }^{\mathbf{1 5}}$ although the overall amount of exposed surface area is lowered. Despite the potential increase in DSSC efficiencies, obtaining these structures using $\mathrm{TiO}_{2}$ can be extremely difficult. Therefore, to overcome this issue, $\mathrm{ZnO}$ has been proposed as an alternative material in DSSCs. ${ }^{3,16-19}$ Compared to $\mathrm{TiO}_{2}, \mathrm{ZnO}$ presents a similar band gap, improved electronic properties, such as higher electron mobility, as well as the ability to grow in both $1 \mathrm{D}$ and 2D morphologies through simple techniques ${ }^{20}$ (e.g. hydrothermal growth). ${ }^{21}$

Although several studies have already described the properties of $1 \mathrm{D}$ and $2 \mathrm{D} \mathrm{ZnO},{ }^{22-25}$ as well as their use as photoanodes in DSSCs, few studies have explored the use of more complex 3D ZnO structures in DSSCs. This lack of investigation might be due to the difficulty of nucleating a secondary $\mathrm{ZnO}$ structure on the surface of the nanorod. Generally, this secondary structure requires that the surface of the nanorod is covered with a new seed-layer, which is usually obtained by the immersion of the primary nanorod in a very dilute organic zinc salt solution and by the subsequent conversion of these seed-layers into $\mathrm{ZnO}$ nanoparticles by annealing. ${ }^{26}$ Despite the simplicity of this step, because of the low wettability of the surface of the primary nanorod to organic solvents, it is necessary to repeat this step several times in order to obtain a uniform and dense seed-layer on the surface of the primary nanorod. An alternative approach to fabricate $3 \mathrm{D} \mathrm{ZnO}$ structures with enhanced exposed surface area employs a metal-organic precursor, named layeredhydroxide zinc salt (LHZS), that is able to easily nucleate on different types of surface, ${ }^{27,28}$ including the $\mathrm{ZnO}$ nanorod surface, without the assistance of a seed-layer. Using this method, the LHZS is homogenously deposited on the surface of the nanorods as a film of nanofoils. After the deposition, these nanofoils are annealed at low temperature so that the metalorganic phase is converted into $\mathrm{ZnO}$ nanofoils made of small homogeneous ZnO nanoparticles. This LHZS phase presents a layered brucite-like structure $\left(\mathrm{Mg}(\mathrm{OH})_{2}\right)$ with the general formula $\mathrm{M}(\mathrm{OH})_{x}{ }^{2-}\left(\mathrm{A}^{m-}\right)_{x / m} \cdot n \mathrm{H}_{2} \mathrm{O}$, in which $\mathrm{M}^{2+}$ is the metallic cation (in this case $\mathrm{Zn}^{2+}$ ) and $\mathrm{A}^{m-}$ is the organic counter-ion (i.e. nitrate, citrate or acetate). This structure consists of layers of $\mathrm{Zn}^{2+}$ cations, octahedrally coordinated by six hydroxyl anions, and interlayers of $\mathrm{A}^{m-}$ anions and water molecules, which are intercalated to balance the overall charge of the structure. ${ }^{29} \mathrm{Zhu}$ et $a l^{28}$ reported a similar strategy to increase the nanorod exposed surface area; however likely both the amount of nanofoils on the surface of the bare nanorods and the absence of subsequent annealing lead to DSSC overall efficiency equal to $0.67 \%$ when these 3D structures were employed. Therefore, a detailed study of the optimization of the preparation of this precursor, so that both the amount of exposed surface and the DSSC performance are maximized, is still required.

In this paper, the LHZS phase is employed as a $\mathrm{ZnO}$ precursor so that the surface of pre-existing $\mathrm{ZnO}$ nanorods can be easily covered with $\mathrm{ZnO}$ nanofoils, without the use of any intermediate seed-layer, to obtain a complex 3D structure, named brush-like. Additionally, the influence of the concentration of citrate in the growth solution, as well as temperature, time and atmosphere of the annealing on the morphology of the brush-like structure and the final DSSC performance are studied. As expected, when in the DSSCs bare ZnO nanorods are substituted with the brush-like structures, the conversion efficiency is improved and reaches $1.95 \%$ for the best sample tested.

\section{Experimental section}

\subsection{Deposition of $\mathrm{ZnO}$ thin film}

The ZnO seed-layer was prepared using a polymeric hydrogel precursor containing methanol, as solvent, $\mathrm{Zn}\left(\mathrm{NO}_{3}\right)_{2} \cdot 6 \mathrm{H}_{2} \mathrm{O}$, as cation source, 2,2-dimethoxy-2-phenylacetophenone, as photoinitiator, and poly(ethylene glycol)dimethacrylate (PEG-DMA, $M_{\mathrm{n}}$ 550), as oligomer. This organic precursor was prepared by mixing two intermediate solutions, $\mathrm{A}$ and $\mathrm{B}$, so that the final concentrations of methanol, PEG-DMA and the photoinitiator were $43 \% \mathrm{wt}, 43 \% \mathrm{wt}$ and $8.4 \%$ wt respectively and $\mathrm{Zn}^{2+}$ was $0.3 \mathrm{M}$. Solution A was obtained by mixing $1 \mathrm{~g}$ of PEG-DMA, $0.5 \mathrm{~g}$ of methanol and $0.2 \mathrm{~g}$ of photoinitiator, whereas solution $\mathrm{B}$ contained $0.7 \mathrm{~g}$ of methanol and $1.5 \mathrm{~g}$ of zinc nitrate. The final solution was obtained by mixing $1 \mathrm{~g}$ of solution A with $0.35 \mathrm{ml}$ of solution B. All the chemicals were purchased from SigmaAldrich and used as received. The substrates used in this work were $2 \times 2 \mathrm{~cm}$ glass squares covered with FTO; before the growth these substrates were cleaned with acetone $99.8 \%$ and isopropanol, sonicating for $5 \mathrm{~min}$ and dried at room temperature.

Once the precursor solution was ready, $40 \mu \mathrm{l}$ of this solution was dropped on the substrate and spin coated at $500 \mathrm{rpm}$ for the first 10 seconds and then accelerated up to $1250 \mathrm{rpm}$ for 35 seconds more. Then, the photopolymerization was activated under UV irradiation for $45 \mathrm{~min}$ using two UV lamps $\left(\lambda_{\max }\right.$ $310 \mathrm{~nm}$ ). Finally, the conversion to $\mathrm{ZnO}$ was obtained with thermal degradation in static air at $500{ }^{\circ} \mathrm{C}$ for $1 \mathrm{~h}$.

\subsection{Hydrothermal growth of $\mathrm{ZnO}$ nanorods}

The nanorod growth solution was obtained by mixing $\mathrm{Zn}\left(\mathrm{NO}_{3}\right)_{2} \cdot 6 \mathrm{H}_{2} \mathrm{O}(0.25 \mathrm{mM})$, ammonium hydroxide $(650 \mathrm{mM})$, hexamethylenetetramine (HMT, $0.25 \mathrm{mM}$ ), polyethylenimine (PEI, $2.24 \mathrm{mM}$ ) and deionized (DI) water. All the chemicals were purchased from Sigma-Aldrich and used as received.

Once the solution was ready, the substrate loaded with the ZnO seed-layer described in Section 2.1 was immersed vertically against the wall of the bottle. Then this bottle was sealed and placed in an oven at $90{ }^{\circ} \mathrm{C}$ for $5 \mathrm{~h}$. Finally, the sample was retrieved, rinsed with DI water and dried at room temperature.

\subsection{Hydrothermal growth of $\mathrm{ZnO}$ brush-like structures}

The LHZS growth solution was obtained by pouring under stirring $\mathrm{Zn}\left(\mathrm{NO}_{3}\right)_{2} \cdot 6 \mathrm{H}_{2} \mathrm{O}(80 \mathrm{mM})$, HMT $(80 \mathrm{mM})$, DI water and sodium citrate aqueous with final concentration of $0.904 \mathrm{mM}$ (lower) or $1.808 \mathrm{mM}$ (double). All the chemicals were purchased 
from Sigma-Aldrich and used as received. A $\mathrm{ZnO}$ nanorod sample was immersed in the solution and the hydrothermal treatment was carried out at $60{ }^{\circ} \mathrm{C}$ for $6 \mathrm{~h}$. After the treatment, the sample was retrieved, rinsed with DI water and dried at room temperature. Finally, the conversion to $\mathrm{ZnO}$ nanoparticles was obtained by annealing for a first step at $350{ }^{\circ} \mathrm{C}$ for $1 \mathrm{~h}$ either in air or oxygen atmosphere. In addition to this, some samples underwent a second annealing step in air either at $400{ }^{\circ} \mathrm{C}$ for $10 \mathrm{~min}$ or at $500{ }^{\circ} \mathrm{C}$ for $30 \mathrm{~min}$.

\subsection{DSSC device fabrication}

For the device fabrication, all the $\mathrm{ZnO}$ samples were immersed for $6 \mathrm{~h}$ in a $1: 1 \mathrm{v} / \mathrm{v}$ acetonitrile : tert-butanol solution with N719 $(0.3 \mathrm{mM})$ as dye-sensitizer and chenodeoxycholic acid $(3 \mathrm{mM})$ as co-adsorbent. After removing and washing off the excess dye with ethanol, a $40 \mu \mathrm{m}$ thick Sellotape film was used as a spacer to define the $5 \times 5 \mathrm{~mm}$ active area. The cell was then closed with a platinum-based counter-electrode prepared using a platinum precursor (Platisol-T) on FTO. Finally, the liquid electrolyte Iodolyte HI-30 was added by capillarity force. All the chemicals were purchased from Solaronix and used as received.

\subsection{Characterization}

XRD measurements were performed using a Bruker D8 Advance diffractometer equipped with a $\mathrm{Cu}$ anticathode $\left(\lambda_{\mathrm{CuK} \alpha}=\right.$ $1.541838 \AA$ ) operating at $40 \mathrm{kV}$ and $40 \mathrm{~mA}$ in theta-theta mode by using a step of $0.022 \theta$ degrees and a collection time of $30 \mathrm{~s}$ per step.

HR-SEM measurements were performed by using a TESCAN MIRA 3 XMU Microscope, operating at $30 \mathrm{kV}$ on samples previously coated with a $5 \mathrm{~nm}$ Au layer (Cressington 208HR sputter). Cross-sections of the as-grown samples were prepared by cutting them in the bulk region using a diamond blade.

The dye loading on each sample was tested by recording the absorbance spectra of desorbed dye using a Perkin-Elmer Lambda 950 UV-visible spectroscope. Adsorbed dye was desorbed from the surface of the sample by soaking in $10 \mathrm{ml}$ of a $0.1 \mathrm{M} \mathrm{NaOH}$ solution in $1: 1$ ethanol : DI water.

Finally, the photovoltaic performance of all DSSCs was measured using a solar simulator system (Newport 91160-100) with a SMU Keithley 2400 source meter to obtain the JV curve under $100 \mathrm{~mW} \mathrm{~cm} \mathrm{~cm}^{-2}$ (AM 1.5G) simulated sunlight.

\section{Result and discussion}

\subsection{Structural characterization}

First, ZnO nanorods were grown on an FTO substrate, which had been previously covered with a uniform film of $\mathrm{ZnO}$ seedlayer obtained using a hydrogel precursor. To grow these nanorods, the hydrothermal method was employed: the $\mathrm{ZnO}$ seed-layer was immersed in a growth solution in which ammonium hydroxide and PEI were added in addition to the common reactants HMT and zinc nitrate. When ammonium hydroxide is added to the growth solution, it has been shown to release $\mathrm{NH}_{3}$, which then interacts with zinc ions and forms the complex $\left[\mathrm{Zn}\left(\mathrm{NH}_{3}\right)_{n}\right]^{2+}$ (with $n$ equals to $1,2,3$ or 4 ). Because of the formation of this complex, ammonia acts as a $\mathrm{Zn}^{2+}$ ion buffer and maintains a constant zinc concentration in the solution, slightly higher than the limit of saturation for the heterogeneous precipitation and slightly lower than the limit of saturation for the homogenous precipitation. Therefore, the presence of ammonia suppresses the homogenous precipitation of $\mathrm{ZnO}$ and enhances the heterogeneous precipitation of ZnO nanorods along the [0001] direction and very long nanorods are obtained (details of this synthesis are reported elsewhere) ${ }^{21}$ In addition, the presence of PEI promotes the selective growth of thin $\mathrm{ZnO}$ nanorods along the polar direction [0001]. This is possible since the non-polar surfactant PEI tends to adsorb on the non-polar ZnO faces $\{0110\},\{1100\}$ and $\{1010\}$ and to suppress the growth of the nanorods along the corresponding directions; consequently, the rate of the growth along the [0001] direction increases and the widening of the nanorod remains under control.

As a result of the addition of these two reactants to the growth solution, a dense film of $\mathrm{ZnO}$ nanorods $8.6 \mu \mathrm{m}$ long and $79 \mathrm{~nm}$ wide (aspect ratio 108) with a packing density of 29 nanorod per $\mu \mathrm{m}^{2}$ was obtained after only $5 \mathrm{~h}$ of heating at $90{ }^{\circ} \mathrm{C}$ (Fig. 1). These nanorods also show high quality crystal structure with a preferential growth along the [0001] direction as shown in XRD analysis reported in a previous work. ${ }^{30}$

3D brush-like $\mathrm{ZnO}$ structures were prepared by combining these nanorods with $\mathrm{ZnO}$ nanofoils obtained using a metalorganic precursor. Once the bare nanorods were prepared as described above, the secondary nanofoils were synthesized as described in the Methods. It was observed that during the treatment with the nanofoil growth solution an organometallic phase, known as layered-hydroxide zinc salt (LHZS), nucleates on the entire surface of the nanorods, while a $\mathrm{ZnO}$ phase homogenously precipitates. The organometallic phase grown on the surface of the nanorods must then be annealed to
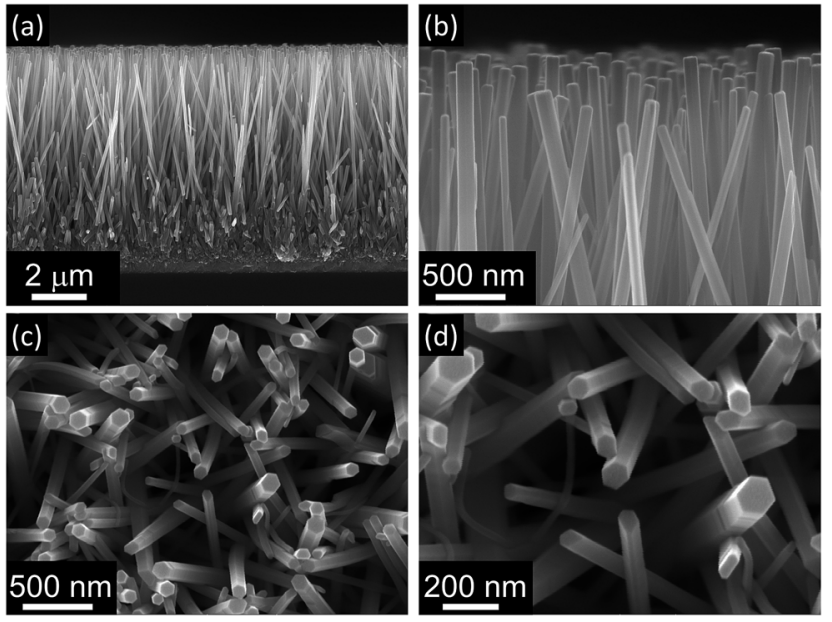

Fig. 1 Cross-section ( $a$ and $b$ ) and top-view ( $c$ and d) SEM images of $\mathrm{ZnO}$ nanorods grown using the hydrothermal method. After heating at $90{ }^{\circ} \mathrm{C}$ for $5 \mathrm{~h}$ nanorods $8.6 \mu \mathrm{m}$ long and $79 \mathrm{~nm}$ wide (aspect ratio 108) with a packing density of 29 nanorod per $\mu \mathrm{m}^{2}$ were obtained. 


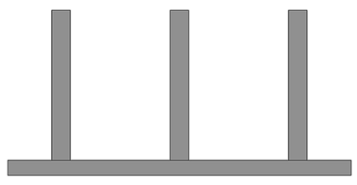

ZnO Nanorods

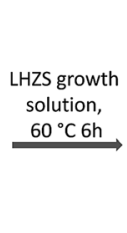

lution,

${ }^{\circ} \mathrm{C} 6 \mathrm{~h}$

convert into ZnO nanofoils. In Fig. 2 a schematic representation of the growth of the brush-like structure is illustrated.

This annealing treatment must be performed at a temperature high enough to completely convert the metal-organic phase into crystalline $\mathrm{ZnO}$ but must not destroy the delicate nanofoil microstructure. Therefore, to find the best annealing conditions, preliminary work was carried out on powdered LHZS. It was clear from FTIR and XRD that the minimum temperature at which most of the organic phase was removed and the LHZS were fully converted in crystalline $\mathrm{ZnO}$ was between $350{ }^{\circ} \mathrm{C}$ and $400{ }^{\circ} \mathrm{C}$ (see ESI $\dagger$ ). Thus, an intermediate annealing condition between those two temperatures $\left(350{ }^{\circ} \mathrm{C}\right.$ for $1 \mathrm{~h}$ plus $400{ }^{\circ} \mathrm{C}$ for $10 \mathrm{~min}$ ) was chosen for this study in an attempt to retain the microstructure and therefore maximise the surface area.

Fig. 3 shows the morphology of nanorod and brush-like structures obtained using different citrate concentrations in
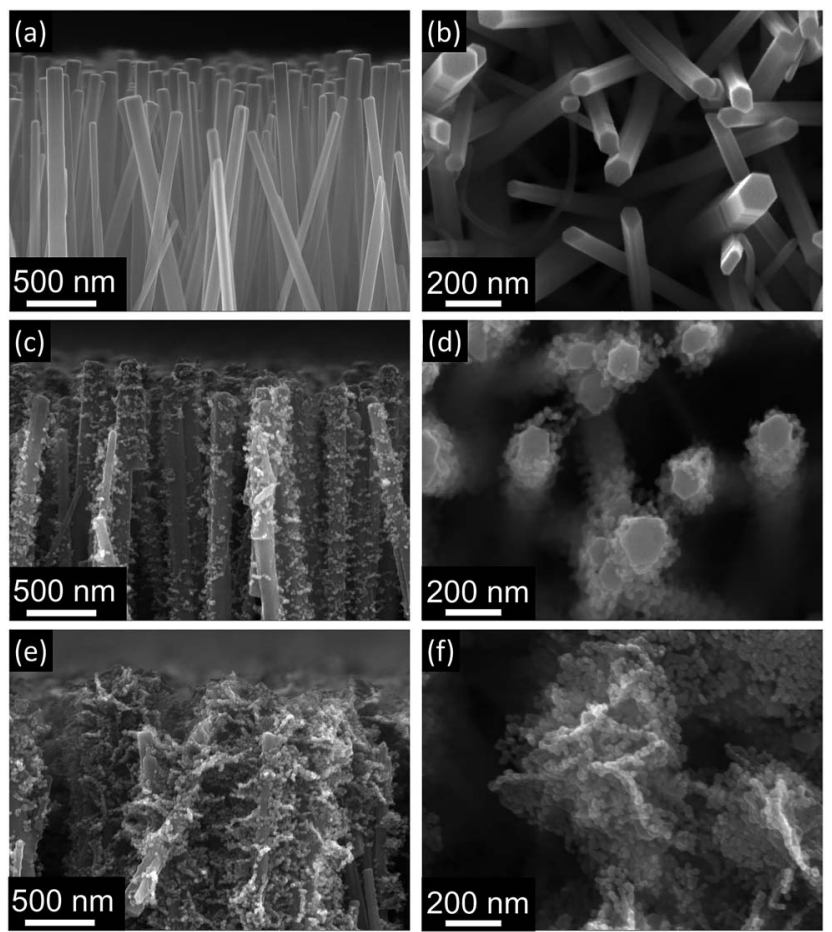

Fig. 3 SEM images of bare nanorods ( $a$ and b) and brush-like structures grown using citrate concentration of $0.904 \mathrm{mM}$ ( $c$ and $d$ ) and $1.808 \mathrm{mM}$ (e and f), respectively. The increase of citrate concentration greatly increases the amount of nanofoils deposited on the surface of the nanorods. the growth solution. It is evident that when a citrate concentration of $0.904 \mathrm{mM}$ (Fig. $3 \mathrm{c}$ and d) was used, a small increase of exposed surface area was achieved compared to bare nanorods (Fig. 3a and b). Whereas, when the concentration of citrate ions in the growing solution was doubled from $0.904 \mathrm{mM}$ (Fig. 3c and d) to $1.808 \mathrm{mM}$ (Fig. 3e and f) and the same annealing parameters were used $\left(350{ }^{\circ} \mathrm{C}\right.$ for $1 \mathrm{~h}$ plus $400{ }^{\circ} \mathrm{C}$ for $\left.10 \mathrm{~min}\right)$, the amount of $\mathrm{ZnO}$ nanofoils on the surface of the nanorods was greatly increased. In addition, it was noticed that when higher concentration of citrate was used, the turbidity of the growth solution decreased, suggesting that the homogeneous precipitation of $\mathrm{ZnO}$ in the solution decreases for higher concentration of citrate. This behaviour suggests that during the LHZS growth there is a competition between the homogeneous precipitation of $\mathrm{ZnO}$ and the heterogeneous precipitation of the LHZS phase. The images in Fig. 3 show that higher concentrations of citrate promote the deposition of LHZS phase. This result suggests that, during the growth, the citrate ions might act either as a catalyst for the heterogeneous deposition or as ligand of $\mathrm{Zn}^{2+}$ ions present in solution. The first effect would result in an increase in the LHZS deposition rate, while the second effect would control the concentration of free zinc ions in the solution, reducing the homogenous precipitation of ZnO. However, from preliminary results it was found that concentrations of citrate higher than $1.808 \mathrm{mM}$ produces excess growth of the nanofoils on the $\mathrm{ZnO}$ nanorod surface, leading to fused structures that reduce, rather than increase the surface area.

\subsection{DSSC performance}

The brush-like structures discussed above were employed as photoanodes in DSSCs prepared using N719 as dye and iodine as liquid electrolyte. Their performance were compared with DSSCs employing bare nanorods as photoanodes. Table 1 summarizes the growth condition, the key DSSC performance and the maximum absorbance of desorbed dye from all the structures under study.

Firstly, Fig. 4 compares the performance of DSSCs using photoanodes based on either nanorods or brush-like structures grown using different citrate concentrations but similar annealing conditions (samples A, B and C).

In Fig. 4 it is shown that if a small amount of nanofoils is grown on the surface of the nanorods, by using the lower citrate concentration (sample B), both the short circuit current density $\left(J_{\mathrm{SC}}\right)$ and the power conversion efficiency (PCE) values only increase slightly compared to the bare nanorods (sample A). 
Table 1 Summary of grown parameters for each structure and related DSSC performance

\begin{tabular}{|c|c|c|c|c|c|c|c|c|}
\hline $\begin{array}{l}\text { Sample } \\
\text { name }\end{array}$ & Structure & $\begin{array}{l}\text { Citrate in growth } \\
\text { solution }(\mathrm{mM})\end{array}$ & Annealing condition & $\mathrm{Abs}^{a}$ & $J_{\mathrm{SC}}\left(\mathrm{mA} \mathrm{cm}{ }^{-2}\right)$ & $V_{\mathrm{oc}}(\mathrm{V})$ & $\mathrm{FF}$ & PCE (\%) \\
\hline A & Nanorod & - & - & 0.195 & $5.0 \pm 0.6$ & $0.563 \pm 0.006$ & $0.41 \pm 0.01$ & $1.2 \pm 0.1$ \\
\hline $\mathrm{C}$ & Brush-like & 1.808 & $350^{\circ} \mathrm{C} \_1 \mathrm{~h}+400{ }^{\circ} \mathrm{C} \_10 \mathrm{~min}$ & 0.372 & $7.49 \pm 0.09$ & $0.55 \pm 0.02$ & $0.452 \pm 0.002$ & $1.87 \pm 0.06$ \\
\hline D & Brush-like & 1.808 & $350^{\circ} \mathrm{C} \_1 \mathrm{~h}+500{ }^{\circ} \mathrm{C} \_30 \mathrm{~min}$ & 0.31 & $5.0 \pm 0.2$ & $0.52 \pm 0.01$ & $0.439 \pm 0.009$ & $1.13 \pm 0.05$ \\
\hline $\mathrm{E}$ & Brush-like & 1.808 & $350^{\circ} \mathrm{C} \_1 \mathrm{~h}$ (oxygen) & 0.448 & $7.97 \pm 0.03$ & $0.567 \pm 0.006$ & $0.433 \pm 0.002$ & $1.95 \pm 0.03$ \\
\hline
\end{tabular}

${ }^{a}$ Absorbance value are obtained by taking the maximum of the UV-visible absorption spectrum of desorbed dye as shown in Fig. 5 .

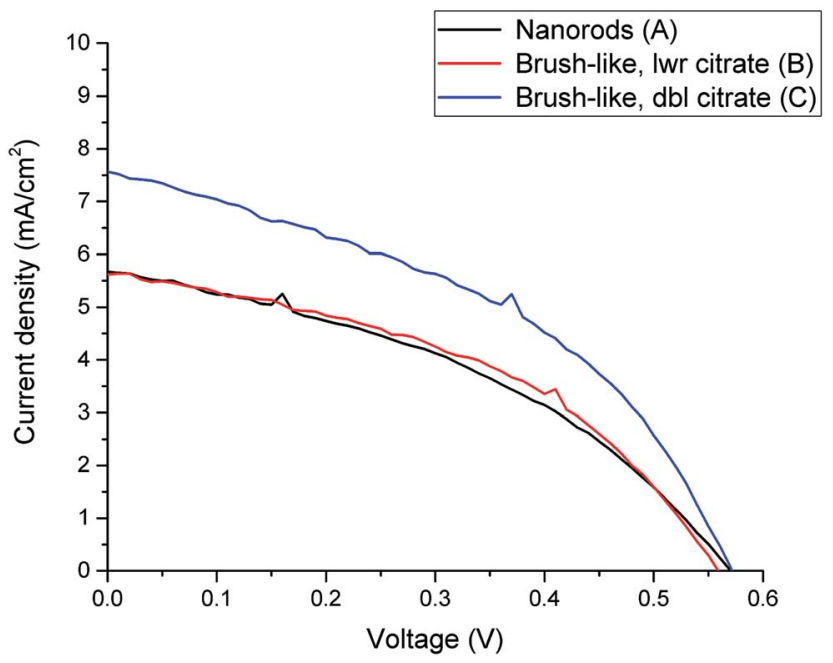

Fig. 4 Current-density vs. voltage curves for DSSC made from nanorods (black line) and brush-like structures grown using lower (red line) and doubled (blue line) concentration of citrate.

Thus, although when 1D nanorods are substituted with this 3D brush-like structures the amount of adsorbed dye on the surface increases (Fig. 5 and Table 1), the performance of the two

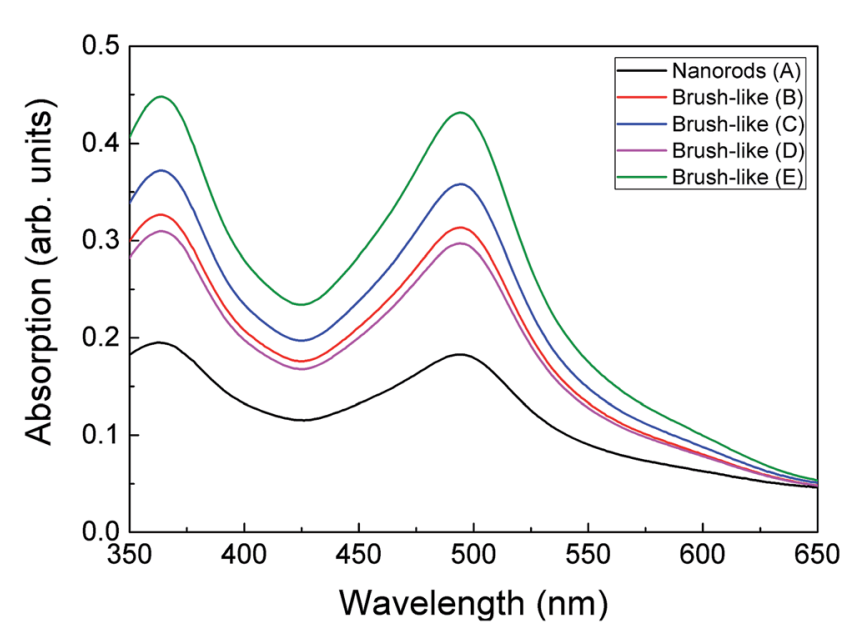

Fig. 5 UV-visible absorption spectrum of dye desorbed from the surface of $\mathrm{ZnO}$ nanorods and brush-like structures, which were grown with different citrate concentrations and annealed in different condition. Sample preparation conditions are given in Table 1.
DSSCs, and particularly $J_{\mathrm{SC}}$, does not change significantly. This implies that while the surface area for dye adsorption is increased by the addition of surface structures, other losses may be introduced which limit any enhancements in efficiency. This is discussed further below. However, when the citrate concentration is doubled to $1.808 \mathrm{mM}$ (sample C) $J_{\mathrm{SC}}$ greatly increases from $5.0 \pm 0.6 \mathrm{~mA} \mathrm{~cm} \mathrm{~cm}^{-2}$ for the bare nanorods to $7.49 \pm 0.09 \mathrm{~mA} \mathrm{~cm}{ }^{-2}$ for the brush-like structures obtained using doubled citrate concentration. When the citrate concentration is doubled, the amount of $\mathrm{ZnO}$ nanofoils on the surface of ZnO nanorods significantly increases, as shown in the SEM images (Fig. 3), thus the amount of dye adsorbed on this surface should increase consequently.

The relation between the increase of $J_{\mathrm{SC}}$ and amount of absorbed dye was further investigated using UV-visible analysis of dye desorbed from the surface of the structures (see Methods). Fig. 5 shows the optical absorption of the dye adsorbed onto $\mathrm{ZnO}$ nanorods and 3D brush-like structures, as well as further samples that are discussed below. As expected the absorption is found to be strictly dependent on the amount of surface area available on the different $\mathrm{ZnO}$ structures. In particular, the absorption of the brush-like structures is always significantly higher than the absorption of bare nanorods (sample A), regardless the specific preparation conditions used to obtain the $3 \mathrm{D}$ structures. In addition, when the brush-like structures are prepared using doubled citrate concentration (sample C) the absorbance increases strongly compared to the absorbance related to the structures prepared using lower citrate concentration and same annealing conditions (sample B). This increment in dye absorption and $J_{\mathrm{SC}}$ leads to a significant improvement of PCE, which raises from $1.2 \pm 0.1 \%$ for nanorods to $1.87 \pm 0.06 \%$ for brush-like structures grown using doubled citrate concentration (Table 1).

It is also notable that the fill factor (FF) for all brush-like structures (0.433-0.455) is in fact improved compared to the nanorod-based photoanode $(0.41 \pm 0.01)$, even though the structure of the photoanode changes from a monocrystalline one, such as ZnO nanorods, to a polycrystalline one, such as the $\mathrm{ZnO}$ brush-like structures. As discussed in the Introduction, DSSC efficiency depends not only on the amount of exposed surface area, but also on the path through which the electrons must travel to reach the external circuit. The nanofoils of these brush-like structures are made of $\mathrm{ZnO}$ nanoparticles; thus, when brush-like structures are used as photoanode, the 
electrons have to cross a great number of grain-grain boundaries to reach the external circuit. Despite this, the improvement in FF implies that recombination is lowered in the brushlike structure. This result suggests that the $\mathrm{ZnO}$ nanofoils produced from the LHZS structure may have improved properties for charge transfer from the dye, leading to reduced interfacial recombination that outweighs any increase in recombination at grain boundaries. Further detailed investigation of surface states and charge transfer kinetics at these different interfaces would provide further insight into this possibility, and would therefore be a potential avenue for future study.

To investigate whether reductions in the grain boundaries could improve the efficiency of the devices, photoanodes based on brush-like structures obtained using increased temperature and time in the second annealing step from $400{ }^{\circ} \mathrm{C}$ to $500{ }^{\circ} \mathrm{C}$ and from $10 \mathrm{~min}$ to $30 \mathrm{~min}$ respectively. This stronger annealing condition was chosen based on the preliminary FTIR results (see ESI $\dagger$ ): when the annealing temperature reaches $500{ }^{\circ} \mathrm{C}$, the organic phase is completely removed and the peaks related to the $\mathrm{ZnO}$ structure become more pronounced.

As shown in Fig. 6 (b), when the stronger annealing conditions are employed, the $\mathrm{ZnO}$ nanoparticles composing the nanofoils tend to sinter and grow and, consequently, both the number of grain-grain boundaries and the amount of exposed surface of these brush-like structures decrease.

As shown in Table 1 and Fig. 6 (c), $J_{\mathrm{SC}}$ greatly decreases from $7.49 \pm 0.09 \mathrm{~mA} \mathrm{~cm}^{-2}$ down to $5.0 \pm 0.2 \mathrm{~mA} \mathrm{~cm}^{-2}$ when the stronger annealing was used. The decrease is due to the decrease of dye absorption, which can be observed in the UV-visible
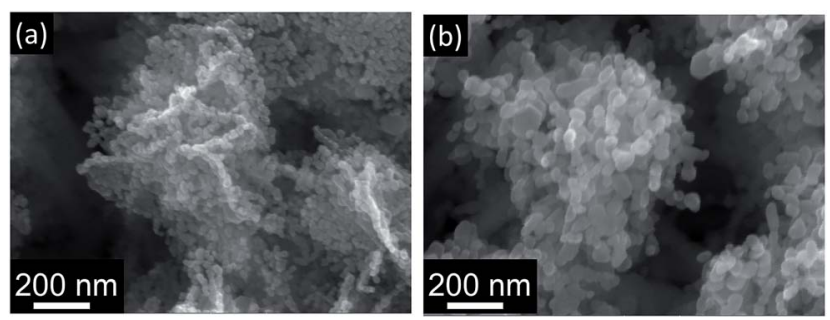

(c)

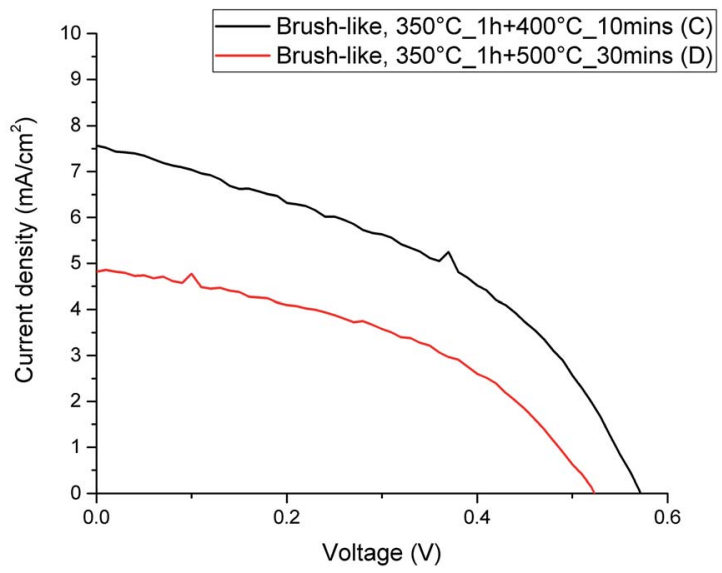

Fig. 6 SEM (a and b) and current-density vs. voltage curves (c) for DSSC made from brush-like structures annealed using more moderate (a) and stronger (b) annealing conditions. absorption results (Fig. 5). Of particular interest is that when the brush-like structure underwent annealing at higher temperature and time (sample D), the absorption is even lower than that obtained using brush-like structure grown in lower concentration of citrate (sample B). This confirms that annealing at high temperatures for long times results in a degradation of the nanofoil microstructure producing only a small increase in the amount of surface area compared to bare nanorods. As a result, the PCE of sample D is much lower $(1.13 \pm 0.05 \%)$ than the one obtained using softer annealing (sample C, $1.87 \pm 0.06 \%$ ).

It is, in fact, interesting to note that even if the number of grain-grain boundaries is much lower in sample $\mathrm{D}$ because of the stronger annealing conditions employed, there is no improvement in the $\mathrm{FF}$ compared to the values of sample $\mathrm{C}$ $(0.452 \pm 0.002)$. This lack of increase means that even if the nature of the electron path is an important factor in DSSC optimization, in this case the amount of exposed surface area appears to be much more influential, thus any benefit gained by reducing the resistivity of the electron path is eclipsed by the decrease of $\mathrm{ZnO}$ exposed surface area.

Since the amount of exposed surface area has such a strong influence on the final DSSC performance, attempts were made to further decrease the annealing temperature at which the brush-like structures were converted. In this case only the first annealing step was used $\left(350^{\circ} \mathrm{C}\right.$ for $\left.1 \mathrm{~h}\right)$. However, as shown in the FTIR results (see ESI $\dagger$ ), after this annealing step most of the organic phase was still present, thus, in order to overcome this limitation and to facilitate the oxidation of this phase, an oxidative environment was used during this annealing (pure $\mathrm{O}_{2}$ ). This was referred to as sample E. Fig. 7 shows the JV curves
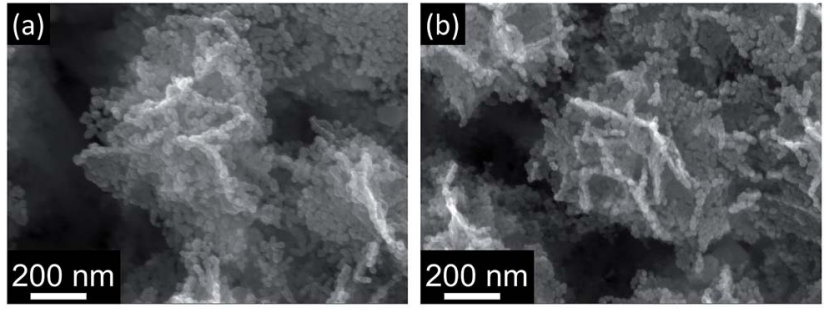

(c)

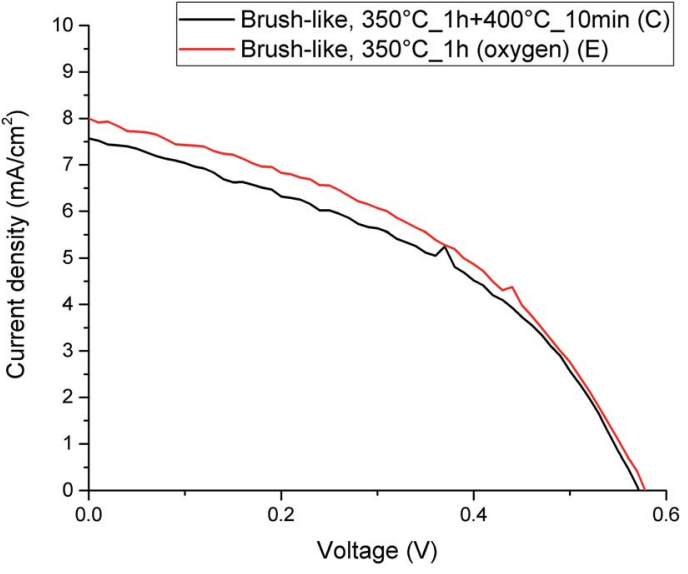

Fig. 7 SEM images ( $a$ and $b$ ) and current-density vs. voltage curves (c) for DSSC made from brush-like structures annealed using 2-step annealing (a) and 1-step (oxygen atmosphere) (b). 
(c) and the SEM images (a and b) of these brush-like structures (sample E) and the structures obtained annealing in air using the second step at $400{ }^{\circ} \mathrm{C}$ for $10 \mathrm{~min}$ (sample C).

The brush-like structures annealed in oxygen (sample E) showed a small $J_{\mathrm{SC}}$ increase from $7.49 \pm 0.09 \mathrm{~mA} \mathrm{~cm}^{-2}$ to $7.97 \pm$ $0.03 \mathrm{~mA} \mathrm{~cm} \mathrm{~cm}^{-2}$, despite the large improvement of exposed surface area and dye absorption (Fig. 5). These results might imply that, despite the increased surface area obtained by reducing the annealing temperature (as shown by absorption spectra: Fig. 5), this was not translated in an equivalent improvement of $J_{\mathrm{SC}}$ in the DSSC device. It is likely that this discrepancy is due to an increase of recombination probability of electrons from the surface of the structure to the external circuit. These recombination events might be caused either by a great increase of the number of grain boundaries or by the presence of oxygen-related defects introduced by the annealing atmosphere. Again, detailed investigation of such processes would be an interesting area for future study.

Therefore, when a lower annealing temperature is employed, in combination with the use of oxygen atmosphere, the DSSC performance improves slightly, leading to an overall PCE equal to $1.95 \pm 0.03 \%$, but the improvement is lower than expected based on the increased dye loading (Fig. 5).

By comparing the PCE of the DSSCs with the optical absorption of the desorbed dye (Fig. 8), it can be seen that in general these two parameters correlate well. This is to be expected since, as stated, the amount of surface area available and therefore amount of dye adsorbed onto the surface is an important factor in determining the PCE by influencing the light absorption and therefore $J_{\mathrm{SC}}$. However, it is also interesting to note that some samples show slightly lower PCE than expected from the UV-visible absorption, such as when higher temperature and time annealing was used (sample D), or when an oxygen annealing atmosphere was used (sample E). This highlights that further factors beyond surface area and dye

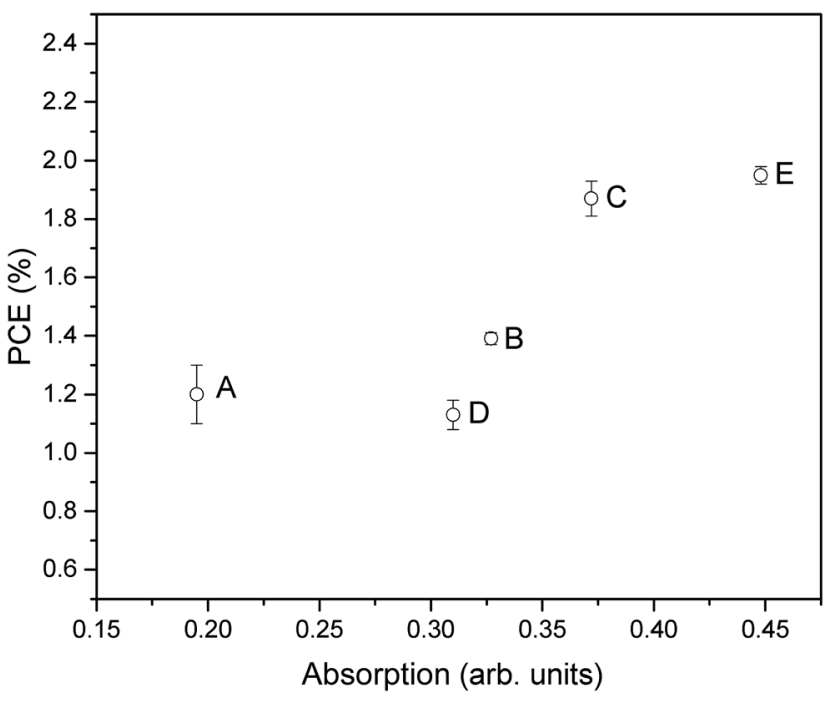

Fig. 8 Optical absorbance vs. PCE plot showing the relationship between the amount of exposed surface area and the final DSSC performance. adsorption can be influenced by the annealing such as surface states and therefore charge transfer and recombination processes as already discussed. However, in general this does highlight that given the optimum annealing conditions, the efforts discussed here to maximize available surface area through careful deposition and treatment of surface structures can be very beneficial for increasing the available surface area for dye adsorption and therefore PCE.

\section{Conclusion}

In this study 3D ZnO structures, named brush-like, have been proposed as an alternative DSSC photoanode material. These innovative structures were prepared by covering the surface of ZnO nanorods with nanofoils deposited using layeredhydroxide zinc salt (LHZS) as a metal-organic precursor. This metal-organic precursor was then converted in $\mathrm{ZnO}$ nanofoils using two-step annealing. When bare $\mathrm{ZnO}$ nanorods were substituted with these 3D structures as a DSSC photoanode, a consistent increase of both $J_{\mathrm{SC}}$ and PCE have been reported, up to maximum values of $7.97 \pm 0.03 \mathrm{~mA} \mathrm{~cm}{ }^{-2}$ and $1.95 \pm$ $0.03 \%$ respectively. This enhanced performance is the result of the systematic optimization of the brush-like structure preparation process. First it has been found that higher concentrations of citrate in the growth solution promote the deposition of the LHZS phase at the expense of the homogenous precipitation. Therefore, as shown in SEM images, when higher concentrations of citrate were employed, larger amount of exposed surface area was obtained. This result agrees with both UV-visible analysis and DSSC test results, which show higher optical absorption (0.37) and higher PCE (1.87\%) when higher citrate concentrations were used in the growth solution. In addition, the annealing parameters were optimized. This annealing step is necessary to convert the LHZS phase in fullycrystalline $\mathrm{ZnO}$ nanoparticles without destroying the nanofoil arrangement. It has been found that performing this annealing step in pure oxygen at $350{ }^{\circ} \mathrm{C}$ for only $1 \mathrm{~h}$ was sufficient to fully convert the LHZS phase in ZnO and obtain the highest DSSC performance reported in this study (absorption 0.45; PCE $1.95 \%)$.

These results suggest that these innovative $3 \mathrm{D} \mathrm{ZnO}$ structures are a promising substitute for common 1D ZnO structures, such as nanorods, as a photoanode. When these brush-like structures are employed as DSSC photoanodes the $J_{\text {SC }}$ dramatically increases due to the large amount of surface area exposed by these structures. In addition, it has been observed that even if the electron path from the adsorbed dye to the external circuit presents a large number of grain-grain boundaries, the FF values of these 3D structures are comparable to those of the bare nanorods. Therefore, when these structures are employed the probability of recombination processes does not appear to increase. However, despite these improvements the maximum efficiency remains below $2 \%$, where efficiencies of up to $10 \%$ are achievable using similar dye-electrolyte systems in combination with mesoporous $\mathrm{TiO}_{2}$ photoanodes. ${ }^{7}$ Considering that maximum efficiencies similar to the ones achieved in this work are reported in related literature on $\mathrm{ZnO}$ 
nanostructures in DSSCs, ${ }^{\mathbf{3 , 1 6 - 1 9 , 2 2 - 2 5}}$ this supports the conclusion that there are fundamental limitations to the use of $\mathrm{ZnO}$ nanostructures in DSSCs. Despite this, the overall findings reported herein - that through careful control of processing conditions an optimum hierarchical nanostructure can be produced with a careful balance between optimised surface area and conductive pathways - are highly relevant beyond this single application. The ability to directly observe the impact of these conditions on both dye adsorption and device performance parameters make the study of DSSCs extremely useful tool to understand this balance. The optimised structures identified through this development may, however, offer the greatest advantages when applied to wider fields where high surface area and good charge transport are also required, such as photoelectrocatalysis, and gas- or bio-sensing.

\section{Conflicts of interest}

There are no conflicts to declare.

\section{Acknowledgements}

The authors would like to thank CISRiC (Centro Interdipartimentale di Studi e Ricerche per la Conservazione del Patrimonio Culturale, University of Pavia) for the use of the scanning electron microscope. J. B. would like to acknowledge funding from Innovate UK project 101796.

\section{References}

$1 \mathrm{H}$. Antonio and S. Hegedus, Handbook of photovoltaic science and engineering, 2003.

2 M. A. Green, Sol. Energy, 2004, 76, 3-8.

3 Q. Zhang, C. S. Dandeneau, X. Zhou and G. Cao, Adv. Mater., 2009, 21, 4087-4108.

4 V. Thavasi, V. Renugopalakrishnan, R. Jose and S. Ramakrishna, Mater. Sci. Eng., R, 2009, 63, 81-99.

5 A. Omar and H. Abdullah, Renewable Sustainable Energy Rev., 2014, 31, 149-157.

6 J. Gong, J. Liang and K. Sumathy, Renewable Sustainable Energy Rev., 2012, 16, 5848-5860.

7 B. O'Regan and M. Gratzel, Nature, 1991, 353, 737-740.

8 K. Kakiage, Y. Aoyama, T. Yano, K. Oya, J. Fujisawa and M. Hanaya, Chem. Commun., 2015, 51, 15894-15897.

9 H. Chang, Y. J. Yang, H. C. Li, C. C. Hsu, I. C. Cheng and J. Z. Chen, J. Power Sources, 2013, 234, 16-22.
10 H. Chang, C. M. Hsu, P. K. Kao, Y. J. Yang, C. C. Hsu, I. C. Cheng and J. Z. Chen, J. Power Sources, 2014, 251, 215-221.

11 J. T. Hong, H. Seo, D. G. Lee, J. J. Jang, T. P. An and H. J. Kim, J. Electrost., 2010, 68, 205-211.

12 K. D. Benkstein, N. Kopidakis, J. van de Lagemaat and A. J. Frank, J. Phys. Chem. B, 2003, 107, 7759-7767.

13 B. Liu and E. S. Aydil, J. Am. Chem. Soc., 2009, 131, 39853990.

14 W.-Q. Wu, Y.-F. Xu, C.-Y. Su, D.-B. Kuang, B. O'Regan and M. Grätzel, Energy Environ. Sci., 2014, 7, 644-649.

15 S. H. Kang, S.-H. Choi, M.-S. Kang, J.-Y. Kim, H.-S. Kim, T. Hyeon and Y.-E. Sung, Adv. Mater., 2008, 20, 54-58.

16 U. V Desai, C. Xu, J. Wu and D. Gao, Nanotechnology, 2012, 23, 205401.

17 L. Liu, K. Hong, X. Ge, D. Liu and M. Xu, J. Phys. Chem. C, 2014, 118, 15551-15555.

18 Y. K. Mishra and R. Adelung, Mater. Today, DOI: 10.1016/ J.MATTOD.2017.11.003.

19 B. Kılıç, E. Gür and S. Tüzemen, J. Nanomater., 2012, 2012, $1-7$.

20 Z. L. Wang, J. Phys.: Condens. Matter, 2004, 16, R829-R858.

21 A. Resmini, I. G. Tredici, C. Cantalini, L. Giancaterini, F. De Angelis, E. Rondanina, M. Patrini, D. Bajoni and U. AnselmiTamburini, J. Mater. Chem. A, 2015, 3, 4568-4577.

22 Y. Qiu, K. Yan, H. Deng and S. Yang, Nano Lett., 2012, 12, 407-413.

23 W. Chen, H. Zhang, I. M. Hsing and S. Yang, Electrochem. Commun., 2009, 11, 1057-1060.

24 A. B. F. Martinson, J. W. Elam, J. T. Hupp and M. J. Pellin, Nano Lett., 2007, 8, 2183-2187.

25 Z. Liu, Y. Li, C. Liu, J. Ya, W. Zhao, L. E, D. Zhao and L. An, Solid State Sci., 2011, 13, 1354-1359.

26 C. P. Grigoropoulos and H. J. Sung, Nano, 2010, 666-671.

27 K. Kakiuchi, E. Hosono, T. Kimura, H. Imai and S. Fujihara, J. Sol-Gel Sci. Technol., 2006, 39, 63-72.

28 S. Zhu, L. Shan, X. Tian, X. Zheng, D. Sun, X. Liu, L. Wang and Z. Zhou, Ceram. Int., 2014, 40, 11663-11670.

29 G. G. C. Arizaga, K. G. Satyanarayana and F. Wypych, Solid State Ionics, 2007, 178, 1143-1162.

30 I. G. Tredici, A. Resmini, F. Yaghmaie, M. Irving, F. Maglia and U. Anselmi-Tamburini, Thin Solid Films, 2012, 526, 22-27. 